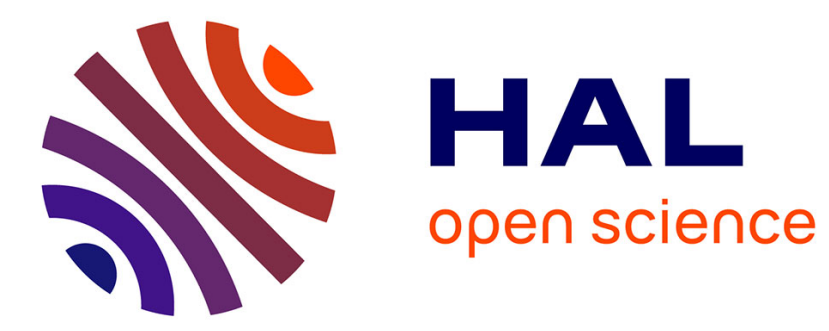

\title{
A bilinear input-output model with state-dependent delay for separated flow control
}

Maxime Feingesicht, Cédric Raibaudo, Andrey Polyakov, Franck Kerherve, Jean-Pierre Richard

\section{> To cite this version:}

Maxime Feingesicht, Cédric Raibaudo, Andrey Polyakov, Franck Kerherve, Jean-Pierre Richard. A bilinear input-output model with state-dependent delay for separated flow control. European Control Conference 2016, Jun 2016, Aalborg, Denmark. hal-01298166

\section{HAL Id: hal-01298166 https://hal.inria.fr/hal-01298166}

Submitted on 5 Apr 2016

HAL is a multi-disciplinary open access archive for the deposit and dissemination of scientific research documents, whether they are published or not. The documents may come from teaching and research institutions in France or abroad, or from public or private research centers.
L'archive ouverte pluridisciplinaire HAL, est destinée au dépôt et à la diffusion de documents scientifiques de niveau recherche, publiés ou non, émanant des établissements d'enseignement et de recherche français ou étrangers, des laboratoires publics ou privés. 


\title{
A bilinear input-output model with state-dependent delay for separated flow control
}

\author{
Maxime FEINGESICHT ${ }^{1,2,4}$, Cédric RAIBAUDO ${ }^{1,3}$, Andrey POLYAKOV ${ }^{2,4}$, Franck KERHERVE ${ }^{1,3}$ \\ and Jean-Pierre RICHARD ${ }^{1,2,4}$
}

\begin{abstract}
It is proposed a first step to the model-based closedloop control of a separated flow. In such situations, fluid mechanics phenomena are highly nonlinear and can be represented by means of the Navier-Stokes equations. However, such a model still rises difficult issues for control practice. This paper proposes an alternative, bilinear and delayed model, the accuracy of which is studied. The identification technique combines least-square technique with a Mesh Adaptive Direct Search (MADS) algorithm. The main feature of the model is state dependent structure of input delay.
\end{abstract}

\section{INTRODUCTION}

In transportation systems, aerodynamic loss are the most important source of energy wastage at speeds higher than $50 \mathrm{~km} / \mathrm{h}$. The need of improvement cannot be met solely through the use of the vehicle shape, as it requires numerous tries for very few improvement, thus being very time consuming. In such a context, active control strategies are now expected.

Among the various strategies developed, those using pneumatic actuators, such as air blowers, are the most encountered. In the meantime, the preferred examined system concerns flow separating over a two-dimensional flap (see [1], [2], [3], [4] and [5]). These works generally study the system from the Fluid Mechanics point of view but the application of control theory should be fruitfull to control the opening and closing of the air blowers in an optimal and robust way. This is only possible once the model representing the system has been identified. Examples of separated flow control can be found in [6], [7] and [8], however these examples suffer from the lack of an adequate model. Modeling using Navier-Stokes equations can be found in [9], [10] and [11].

The main issue is that the physical system studied in this paper is known to be highly nonlinear, which is always the case in aerodynamic studies, and also contains time delays both on state and input due to the natural phenomenons that rule turbulent flow and the limited speed of the flow. The first approach would be to use partial differential equations, namely the equations of Navier-Stockes, but this implies complicated calculations and controller/observer design. The alternative we propose is to use "greybox" identification techniques so to derive a simpler model that can be usefull for control purpose. The model we suggest is a bilinear, delayed difference equation which is able to catch both the nonlinear effects and diffusion delays. Such a model will be shown to be quite realistic in an identification perspective. From

\footnotetext{
${ }^{1}$ Ecole Centrale de Lille, Cité Scientifique, 59651 Villeneuve-d'Ascq, France

maxime.feingesicht@ec-lille.fr ; cedric.raibaudo@ec-lille.fr

franck.kerherve@ec-lille.fr ; jean-pierre.richard@ec-lille.fr

${ }^{2}$ INRIA Team Non-A, Parc scientifique de la Haute-Borne, 40 Avenue Halley, Bt A - Park Plaza, Villeneuve-d'Ascq, France andrey.polyakov@inria.fr

${ }^{3}$ LML, Laboratoire de Mécanique de Lille, CNRS UMR 8107, Boulevard Paul Langevin, 59655 Villeneuve d'Ascq Cédex, France

${ }^{4}$ CRIStAL, CNRS UMR 9189, Btiment M3, Université Lille 1, 59655 Villeneuve d'Ascq Cedex FRANCE
}

the control point of view, predictor-based ([12]), model predictive control (MPC, [13], [14]) and optimal control techniques ([15]) are possible future solutions.

This paper focuses on the identification of the model based on several experimental data sets. It presents the time delayed input/output model. The simplest scheme for input delay estimation is developed. The state delays identification is provided using the well-known derivative-free minimization algorithm MADS [16]. Some results on the identification of the delays for a related system can also be found in [17].

\section{THE PHYSICAL SYSTEM}

The physical system considered is a turbulent boundary layer developing along a ramp and subjected to separation due to the presence of a inclined flap with a sharp edge whose photography is shown in Fig. 2 with schematics in Fig. 1. The experiments were conducted in the LML boundary layer wind tunnel. The wind tunnel includes a $20 \mathrm{~m}$ long section with constant area of $2 \mathrm{~m} \mathrm{x}$ $1 \mathrm{~m}$ along which the boundary layer can develop. The maximum free stream mean velocity and turbulence level are $10 \mathrm{~m} / \mathrm{s}$ and $0.03 \%$ respectively. Under operation, the temperature is regulated to $0.2 \mathrm{C}$. Full details of the wind tunnel and its characterisation can be found in [18]. The main flow direction is from left to right, except in a region close to the flap where the flow is reversed indicating the presence of a recirculation region due to a separation of the flow away from the wall. The mean streamwise velocity component is measured using Particle Image Velocimetry (PIV). This is illustrated in Fig. 4. This recirculation region is mainly responsible for aerodynamic loss. Control applications are hence designed with the objective to reduce (or annihilate) this reversed flow. In the present case, air blowing actuators were used. These are located upstream of the sharp edge and consist of 22 round jets regularly spaced in the spanwise z-direction as illustrated in Fig. 1. Details of the set-up can be found in [1] and [18]

Real-time survey of the flow is effected thanks to wall-sensors measuring the friction gain mounted along the inclined flap. These are known as hot-film sensors. Again, full details of the arrangements can be found in [1]. The actuators are controlled using a pulsed voltage as command law such as illustrated in Fig. 6. In practice, such sequences are repeated continuously over a long time: the flow is therefore repeatidly submitted to control during which it experiences successive reattachments (actuation on) and separation (actuation off) sequences. The friction gain is continuously recorded during all these sequences and an averaged response can be obtained. The latter is reported in Fig. 3. Since the flow dynamics in the separation region is strongly dependent on several inflow conditions, the instantaneous response of the wallsensor may significantly vary from this averaged response. A first indication of how much the wall-sensor response varies may be obtained by repeating the operation described previously. Different sets of long measurements were effected. For each, an averaged 


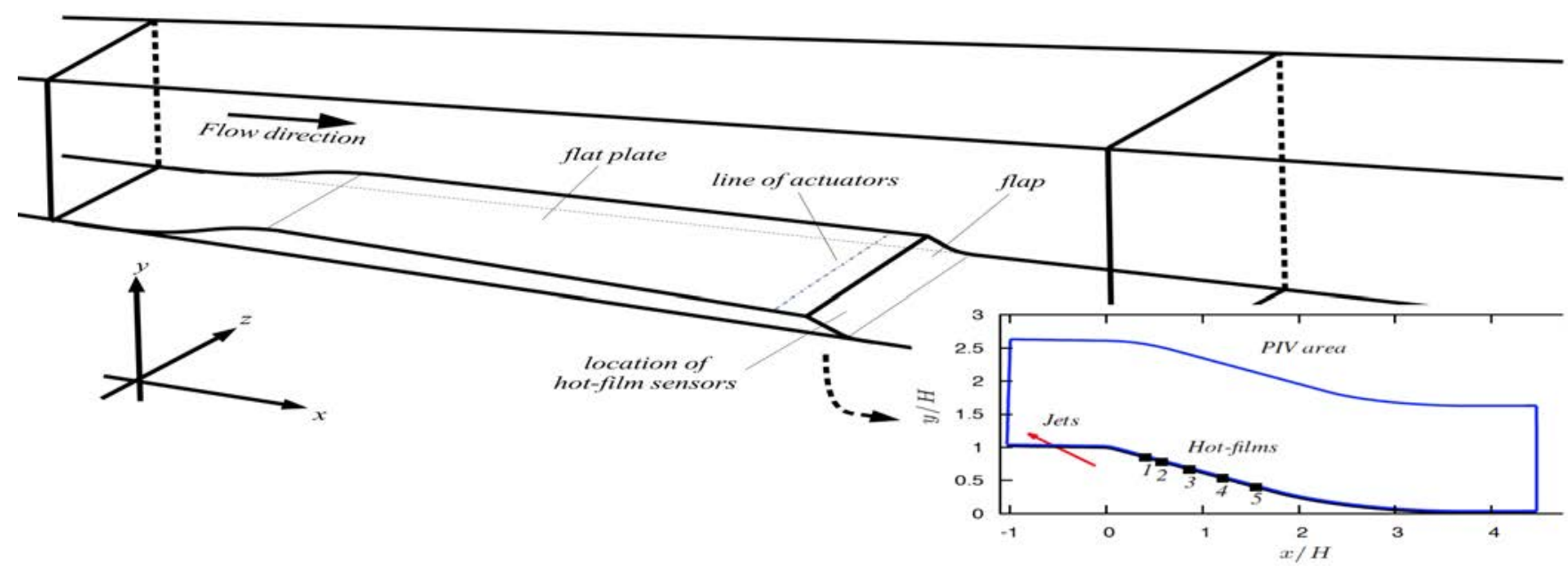

Fig. 1: Schematics of the experimental set-up. Enlarged picture: ramp model. Zoom: region of the flap with locations of the hot-film sensors and active air blowers

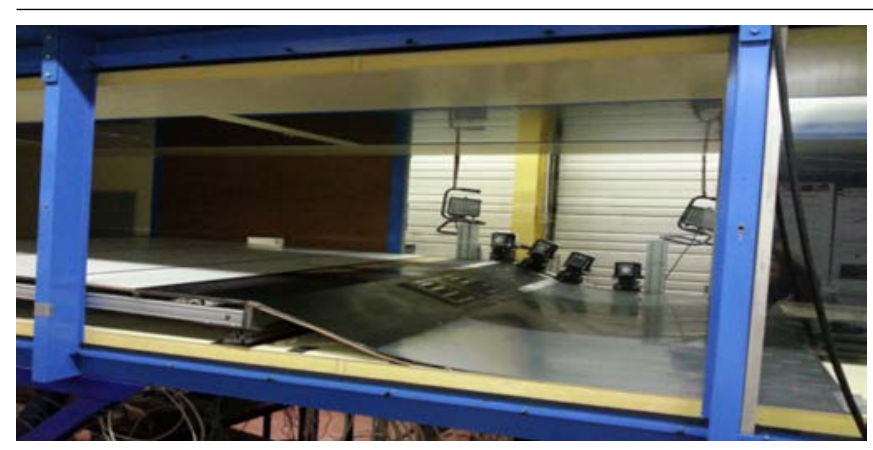

Fig. 2: Photography of the ramp model. The flow is coming from the left

response of the wall-sensor is calculated and the overall data set obtained can be used to bound the averaged response as shown in Fig. 5.

When the actuators are activated $(\mathrm{t}=0 \mathrm{~s})$ contra-rotating vortices are generated (see [1]). Due to the distance between the actuators and the wall-sensors, a time-delay is necessary before the hot-film can sense changes in the flow dynamics. The main effect of the actuators is to force the flow to reattach to the flow, leading to an increase in the friction gain. This increase is manifest when examining the averaged hot-film response of Fig. 6. Once the flow attained a stationary state under control effect, the friction gain remains almost constant. When the control is turned off, again a short time-delay is necessary before the hot-film signal can sense flow changes towards the natural separated state.

Using the available data, it is necessary to develop an input-output model describing the behavior of the hot-film, where the input will be the voltage input to the air blowers and the output will be the voltage output of the hot-film. Considering what was said before, the model need to be time-delayed and will be bilinear in order to catch the nonlinearities of the physical system while remaining simple enough for observation and control.

For our identification process, we will use the four data sets presented in Fig. 3, 6, 7 and 9. The maximum and minimum data can therefore be used for testing purpose in order to verify if the identified system remains within acceptable bounds (see [1] and [2]). These data sets use, respectively, a square wave at a frequency of $8 \mathrm{~Hz}$ and $50 \%$ duty cycle, $4 \mathrm{~Hz}$ and $80 \%$ duty cycle, $4 \mathrm{~Hz}$ and duty cycle of $50 \%$ and a step input.

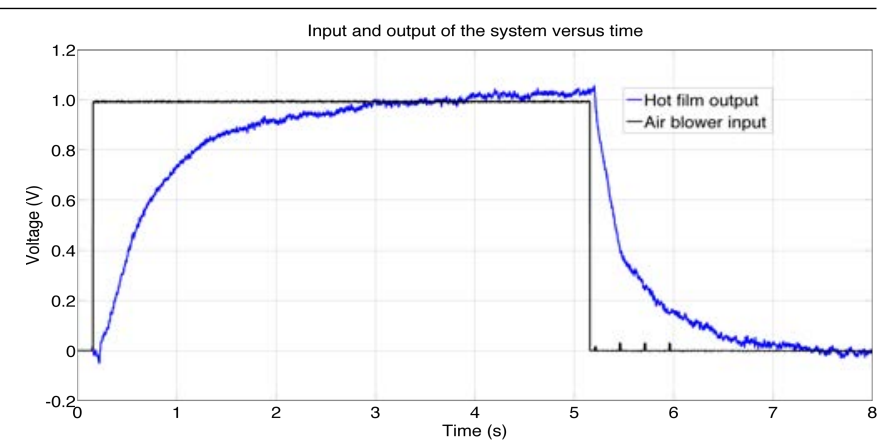

Fig. 3: Set of data $\mathrm{N}^{\circ} 1$ used for identification

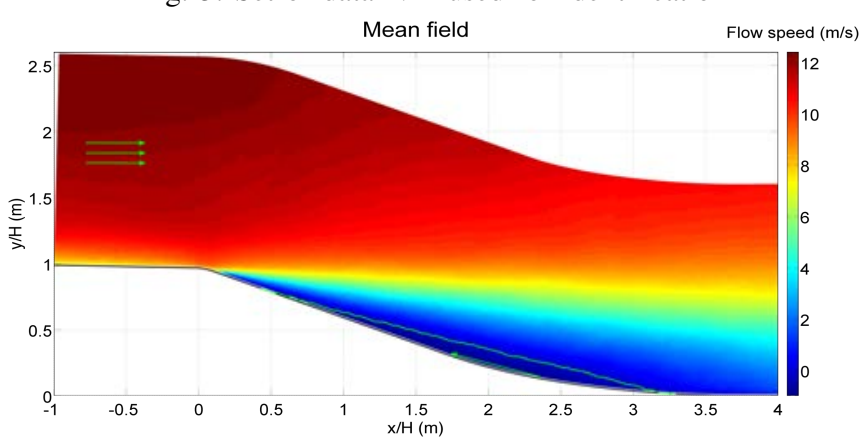

Fig. 4: Mean flow velocity field (streamwise component) in $\mathrm{m} / \mathrm{s}$. The green line delimits the recirculation region where the flow is reversed compared to the main direction. The main flow is from left to right.

\section{SYSTEM IDENTIFICATION}

\section{A. Estimation of the input delay}

The motivation behind using a state-dependent input delay are based on physical considerations : if the air blower is placed before the flap and the hot-films on the flap, the air flow will take some time to travel the distance between them, thus implying a delay which depends on the speed of the flow. As the hot-film output is a measure of the friction in the flow which is related to the speed of the flow and the delay depends on the speed of the flow, the delay can hence be directly estimated from the output of the hot-film.

We then need to obtain the function giving the state-dependent input delay, which will be noted $\tilde{h}\left(y_{k}\right)$. The delays between a 


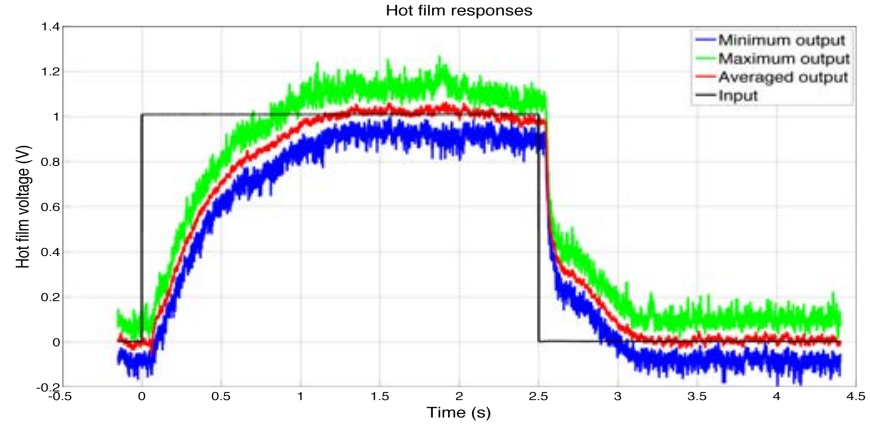

Fig. 5: Voltage output of one hot-film

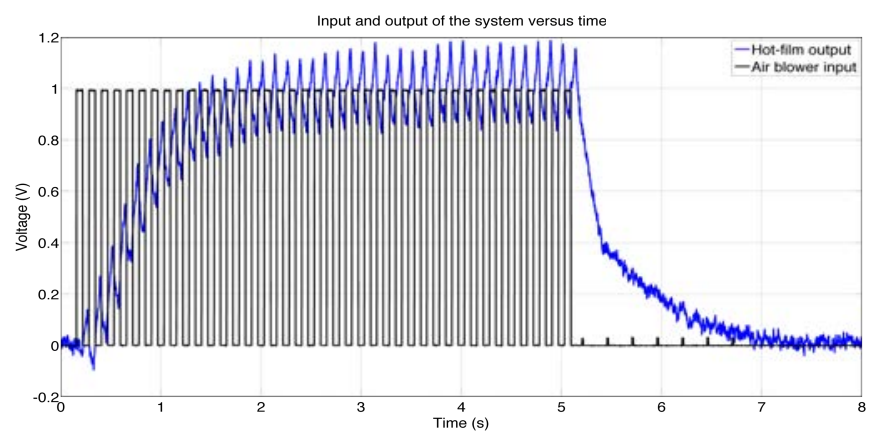

Fig. 6: Hot-film output voltage versus the air blower input voltage for data set $n^{\circ} 4$

variation in the input (on/off, rising or falling edge) and the corresponding variation in the hot-film signal can be measured directly from the data using Matlab functions. For the set of data $\mathrm{N}^{\circ} 2$, this is represented on Fig. 7. In order to take in account the prehistory of the state-function of the time-delayed system in a simple way, the function giving the delay will be evaluated using the mean value (averaged value) of this function, which corresponds to measure the value on an averaged, smoother model, as described in (1).

$$
\widetilde{y_{k}}=\frac{1}{W} \sum_{s=1}^{W-1} y_{k-s}
$$

where $W$ is the averaging window, chosen equal to 250 in our simulations and $y_{k}$ is the output of the system at sample $k$

As the system has short time constants, once the time delay has expired, reaction to the input is very fast, thus our method will not be influenced by the phase of the system and will give sufficiently good estimation of the input delays.

Applying this to the 4 data sets and plotting the measured delays versus the hot-film output value, we obtain Fig. 8. The fitting is

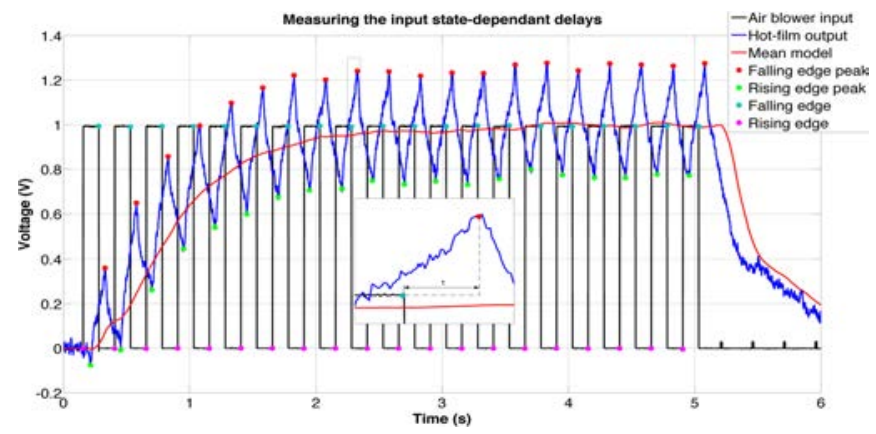

Fig. 7: Identification of the input state-dependent delay for data set $\mathrm{N}^{\circ} 2$ done using Matlab's "fit" function. It is to be noted that applying the fitting to only one of the data sets gives very similar results but using all 4 sets is more reliable.

The fitted function is given by (2).

$$
\widetilde{h}\left(\widetilde{y_{k}}\right)=47.35+12.69 \mathrm{e}^{-20.18 \widetilde{y_{k}}}
$$

where $\tilde{y}_{k}$ is the averaged system output as defined in Eq. 1 and $\widetilde{h}\left(\widetilde{y_{k}}\right)$ is the state dependent input delay that will be used in the identified model in the next section.

A linear statistical analysis on the values of the state-dependent input delay for the fitting presented in Fig. 8 gives the following values :

- Mean $=47.83$

- Standard deviation $=2.70$

- Correlation coefficient with the model input $=-0.07$

- Correlation coefficient with the model output $=-0.30$

\section{B. Bilinear delayed difference model}

We will use two similar system forms to identify the physical process. Both of the forms are bilinear, the first one, given by (3), uses a fixed input delays while the second one, given by (4), uses state dependent input delays. The model is chosen bilinear in order to be simple enough for easy control design while still capturing nonlinear dynamics of the Navier-Stokes equation, which also contains bilinear terms. The model is chosen to be including time delays in order to have an infinite dimension to be closer to a partial differential equation. Example of modeling with linear first order models can be found in [1], where it can be seen that this type of model capture the mean tendency but not the oscillations around this tendency. It is to be noted that we do not intend to represent exactly the model, as we focus more on simple design control and that a robust control well designed can overcome the inaccuracies of our identified model.

$$
\begin{aligned}
& y_{k+1}=\sum_{i=1}^{N_{1}}\left(a_{i} y_{k-\tau_{i}}\right)+\sum_{l=1}^{N_{3}}\left(b_{l}+\sum_{j=1}^{N_{2}}\left(c_{j l} y_{k-\bar{\tau}_{j}}\right)\right) u_{k-h_{l}} \\
& y_{k+1}=\sum_{i=1}^{N_{1}}\left(a_{i} y_{k-\tau_{i}}\right)+\sum_{l=1}^{N_{3}}\left(b_{l}+\sum_{j=1}^{N_{2}}\left(c_{j l} y_{k-\bar{\tau}_{j}}\right)\right) u_{k-\widetilde{h}_{l}\left(\widetilde{y}_{k}\right)}
\end{aligned}
$$

where $0 \leq k \leq N-1$ is the number of the measure $y$, considering that $y_{j}=0$ for $j<0 ; \tau, \bar{\tau}$ and $h$ are prescribed delays ; $N, N_{1}$, $N_{2}$ and $N_{3}$ are respectively the number of measures y, delays $\tau$, $\bar{\tau}$ and input delays $(h$ or $\widetilde{h}) ; \widetilde{h}_{l}\left(\widetilde{y_{k}}\right)=\operatorname{round}\left(f_{l} \widetilde{h}\left(\widetilde{y_{k}}\right)\right)$ are the state dependent input delays of the second model with $f_{l}$ a multiplicative factor used to derive several state dependent input delays from the delay identification ; $a_{i}, b_{l}$ and $c_{j l}$ are the coefficients to identify.

The variables $N_{1}, N_{2}$ and $N_{3}$ are to be chosen by the user in a compromise between complexity of the model and precision. It

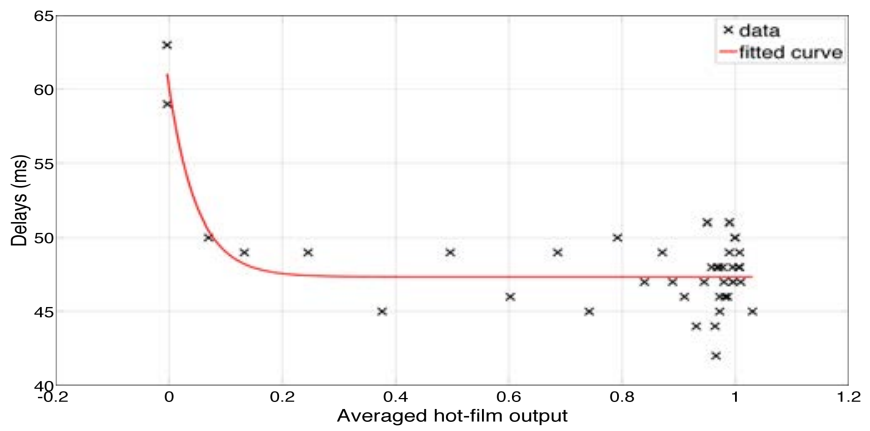

Fig. 8: Fitting of the input state-dependent delays 
will also impact the time required for the optimization used in the identification process. Furthermore, augmenting the size of the model makes control design more complicated. The coefficients used in this paper were found to give good results for our purposes with short enough for efficient computations.

In the continuous time domain, these systems are described by (5) and (6), where $T$ is the sampling period, fixed at $1 \mathrm{~ms}$ for our systems and the function $\widetilde{y}(t)$ is defined by (7).

$$
\begin{aligned}
\dot{y}(t)= & \frac{1}{T}\left(-y(t)+\sum_{i=1}^{N_{1}}\left(a_{i} y\left(t-\tau_{i} T\right)\right)+\sum_{l=1}^{N_{3}}\left(b_{l} u\left(t-h_{l} T\right)\right)\right. \\
& \left.+\sum_{l=1}^{N_{3}} \sum_{j=1}^{N_{2}}\left(c_{j l} u\left(t-h_{l} T\right) y\left(t-\widetilde{\tau}_{j} T\right)\right)\right) \\
\dot{y}(t)= & \frac{1}{T}\left(-y(t)+\sum_{i=1}^{N_{1}}\left(a_{i} y\left(t-\tau_{i} T\right)\right)+\sum_{l=1}^{N_{3}} b_{l} u\left(t-\widetilde{h}_{l}(\widetilde{y}(t)) T\right)\right. \\
& \left.+\sum_{l=1}^{N_{3}} \sum_{j=1}^{N_{2}}\left(c_{j l} u\left(t-\widetilde{h}_{l}(\widetilde{y}(t)) T\right) y\left(t-\widetilde{\tau}_{j} T\right)\right)\right) \\
\widetilde{y}(t)= & \frac{1}{W T} \int_{0}^{W T} y(t-s) d s
\end{aligned}
$$

The identification has been done using a least-square method. We refer the reader to [19] for more details.

To obtain the values of the coefficients contained in the matrix $A_{1}$, we use the Moore-Penrose pseudo-inverse on the matrix $W$. Noting $W^{+}$the Moore-Penrose pseudo-inverse of $W$, we obtain (8).

$$
A(\tau, \bar{\tau}, h, x)=W^{+} x
$$

The quality of the identification will be estimated using the three following indicators : the $L_{2}$ error norm $\varepsilon(\tau, \bar{\tau}, h, A)$ given by (9), the fit coefficient as defined in [20] $\operatorname{FIT}(\tau, \bar{\tau}, h, A)$ given by (10) for the first system and the correlation coefficient between the data and the identified model $\rho(\tau, \bar{\tau}, h, A)$ given by (11) for the first system.

$$
\begin{aligned}
\varepsilon(\tau, \bar{\tau}, h, A) & =\left\|x-x^{\text {simu }}(\tau, \bar{\tau}, h, A)\right\| \\
\operatorname{FIT}(\tau, \bar{\tau}, h, A) & =1-\sqrt{\frac{\sum_{k=1}^{N}\left(y_{k}-y_{k}^{\text {simu }}\right)^{2}}{\sum_{k=1}^{N}\left(y_{k}-\bar{y}_{k}\right)^{2}}} \\
\rho(\tau, \bar{\tau}, h, A) & =\frac{\operatorname{cov}\left(x, x^{\text {simu }}\right)}{\sigma_{x} \sigma_{x^{\text {simu }}}}
\end{aligned}
$$

where $x=\left[y_{0}, y_{1}, \ldots, y_{N}\right]^{T}$ is the vector of data and $x_{1}^{s i m}\left(\tau, \bar{\tau}, h, A_{1}\right)$ is the vector obtained by simulating the system using the identified coefficients, $y_{k}$ is the measured system output (data) at sample $k, y_{k}^{\text {simu }}$ is the simulated system output at sample $k$ using the identified coefficients and $\bar{y}_{k}$ is the average of the measured system output (therefore constant signal). $\operatorname{cov}(\mathrm{X}, \mathrm{Y})$ is the covariance matrix between the vectors $X$ and $Y$ and $\sigma_{X}$ is the standard deviation of the vector $X$.

Please note that, for the system with fixed input delays, we will note these indicators $\varepsilon_{1}$, FIT 1 and $\rho_{1}$ and for the system with statedependent input delays we will note them $\varepsilon_{2}, \mathrm{FIT}_{2}$ and $\rho_{2}$.

As the fixed delays $\tau, \bar{\tau}$ and $h$ and the multiplicative factor $f$, are still to be determined, we can run an optimization algorithm that minimizes $\varepsilon$ in order to find these delays. The chosen algorithm is NOMAD (Nonlinear Optimization with the MADS Algorithm), which is based on the Mesh Adaptative Direct Search (MADS) algorithm. It is capable of blackbox optimization for nonlinear objective functions, with linear and nonlinear equalities and inequalities constraints on continuous, integer or binary variables. NOMAD and the MADS algorithm are very well documented as it can be seen in [21], [16], [22], [23]. NOMAD is implementend in the Opti Toolbox for Matlab, see [24]. For comparison, using Matlab's Genetic Algorithm (ga function) and NOMAD for a maximum of
4000 iterations on a delay optimization problem on the 4 concatened sets gives the following cost functions values : between 1.26 and 1.267 for GA (over 10 tests, it may vary at each test) and 1.2576 for NOMAD. With default settings, NOMAD stops after 4545 functions counts with an objective function value of 1.2571 whereas GA stops after 5200 to 5500 functions counts (over 10 tests) with objective function value of 1.2593 to 1.2643 . Therefore, NOMAD has better performance (lower objective function value), is faster (1000 less function evaluations in the previous test) and is more reliable (every test gives the same results).

The overall algorithm that is used is described as follows:

1) Start

2) Use NOMAD to find the optimal set of delays

3) Calculate the coefficients with the determined set of delays

4) Test the coefficients by simulating the model

5) end

To obtain identified coefficient that best fit the 4 sets of data, and by extension the sets generated for different pulsed inputs, we will apply the identification process to the concatenation of the 4 sets. Notice that each set is ended by a series of 0 for both input and output and for a duration of $1.5 \mathrm{~s}$ over a total of $10 \mathrm{~s}$, the concatenation is possible and the system will have enough time to go back to 0 between each set.

The identification process can finally be applied, leading to Fig. 9 for the simulation results of data set $\mathrm{N}^{\circ} 3$ using identified coefficients. For the 4 concatenated data sets, the least-square errors are $\varepsilon_{1}=10.1529$ for the model with constant input delay and $\varepsilon_{2}=9.7349$ for the model with state-dependent input delay.

The values of the delays values and the identified coefficients can be found in the TABLE II for $N_{1}=5, N_{2}=10$ and $N_{3}=1$. Is is noticeable that the $L_{2}$ norm of the state-dependent input delay model is smaller that the one with fixed delay as it can be seen in the TABLE I, where the $f$ stands for the frequency of the pulses and DC for the duty cycle in case of pulsed input signals.

Comparing to [20], we can see that our fit coefficients are close to the higher coefficients found in the paper. It is noticeable, even if the data are different from the ones used here, that they obtain the best fit coefficients for quasi constant data and for other type of data it rapidly falls under $70 \%$ while here the fit coefficients remain around $90 \%$ for constant of varying inputs with various frequencies and duty cycles. To the author knowledge, there is no other paper presenting model identification with data similar to the ones presented here.

In TABLE $I$ it is noticeable that the correlation coefficient between data and model output is very high, typically around $99.7 \%$, meaning that our model capture well enough the dynamics of the data.

\section{Averaged model}

Based on the idea used to develop $\tilde{y}$ for the state dependent delay identification, we can develop an averaged model using equations (12) and (13). This model will ease the development of control on the system by separating the part with slow dynamics (averaged part) from the one with fast dynamics (difference between nonaveraged and averaged part).

$$
\begin{aligned}
& y_{k}^{a v g}=\frac{1}{W} \sum_{i=0}^{W-1} y_{k-i} \\
& u_{k}^{a v g}=\frac{1}{W} \sum_{i=0}^{W-1} u_{k-i}
\end{aligned}
$$

The averaged models are given by (14) and (15). 
TABLE I: Comparison of $L_{2}$ norm values, FIT coefficients and correlation for state-dependent and fixed input delay models for the complete model

\begin{tabular}{ccccccc} 
Set of data & \multicolumn{3}{c}{ Fixed delay } & \multicolumn{3}{c}{ State-dependent delay } \\
\hline & $\varepsilon_{1}$ & FIT $_{1}$ & $\rho_{1}$ & $\varepsilon_{2}$ & FIT $_{2}$ & $\rho_{2}$ \\
\hline Data set $\mathrm{N}^{\circ} 1$ (constant) & 4.78 & $90.43 \%$ & 0.9981 & 4.69 & $90.61 \%$ & 0.9984 \\
\hline $\begin{array}{c}\text { Data set } \mathrm{N}^{\circ} 2(f=4 \mathrm{~Hz}, \\
D C=50 \%)\end{array}$ & 6.24 & $87.62 \%$ & 0.9964 & 5.70 & $88.70 \%$ & 0.9958 \\
\hline $\begin{array}{c}\text { Data set } \mathrm{N}^{\circ} 3(f=4 \mathrm{~Hz}, \\
D C=80 \%)\end{array}$ & 3.00 & $94.03 \%$ & 0.9984 & 3.07 & $93.90 \%$ & 0.9985 \\
\hline $\begin{array}{c}\text { Data set } \mathrm{N}^{\circ} 4(f=8 \mathrm{~Hz}, \\
D C=50 \%)\end{array}$ & 5.63 & $88.76 \%$ & 0.9961 & 5.10 & $89.82 \%$ & 0.9965 \\
\hline $\begin{array}{c}\text { Data set not used in } \\
\text { identification } \mathrm{N}^{\circ} 1 \\
(\text { constant) }\end{array}$ & 5.33 & $89.58 \%$ & 0.9958 & 5.30 & $89.65 \%$ & 0.9959 \\
\hline $\begin{array}{c}\text { Data set not used in } \\
\text { identification } \mathrm{N}^{\circ} 2 \\
(f=8 \mathrm{~Hz}, D C=80 \%)\end{array}$ & 3.77 & $92.53 \%$ & 0.9972 & 4.01 & $92.04 \%$ & 0.9969 \\
\hline $\begin{array}{c}\text { Concatenated data sets } \\
\text { oncen }\end{array}$ & 10.13 & $89.91 \%$ & 0.9950 & 9.48 & $90.55 \%$ & 0.9955
\end{tabular}

TABLE II: Values of the delays and identified coefficients (all values have No Unit) for the complete model

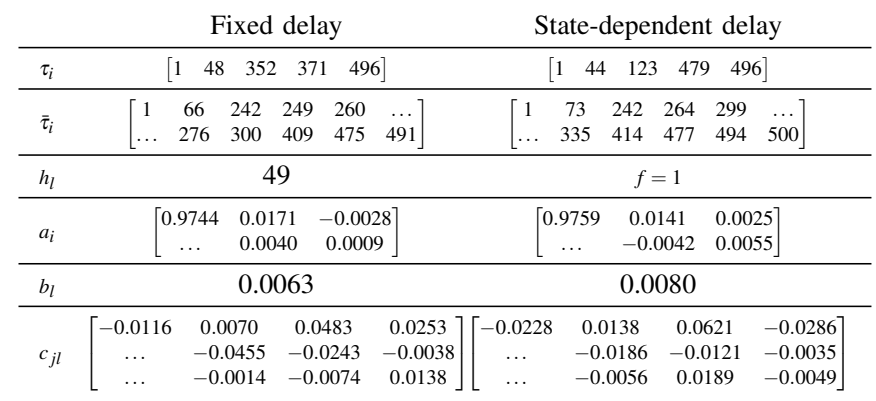

$$
\begin{aligned}
y_{k+1}^{a v g}= & \sum_{i=1}^{N_{1}}\left(a_{i}^{a v g} y_{k-\tau_{i}^{a v g}}^{a v g}\right) \\
& +\sum_{l=1}^{N_{3}}\left(b_{l}^{a v g}+\sum_{j=1}^{N_{2}}\left(c_{j l}^{a v g} y_{k-\bar{\tau}_{j}^{a v g}}^{a v g}\right)\right) u_{k-h_{l}^{a v g}}^{a v g} \\
y_{k+1}^{a v g}= & \sum_{i=1}^{N_{1}}\left(a_{i}^{a v g} y_{k-\tau_{i}^{a v g}}^{a v g}\right) \\
& +\sum_{l=1}^{N_{3}}\left(b_{l}^{a v g}+\sum_{j=1}^{N_{2}}\left(c_{j l}^{a v g} y_{k-\bar{\tau}_{j}^{a v g}}^{a v g}\right)\right) u_{k-\widetilde{h}_{l}^{a v g}\left(y_{k}^{\text {avg }}\right)}^{\text {avg }}
\end{aligned}
$$

For $N_{1}=2, N_{2}=2$ and $N_{3}=2$, the delays and identified coefficients for the averaged model are presented in the TABLE IV. As it can be seen in the TABLE III, applying the same analysis as before for the compelete model, it is noticeable that the $L_{2}$ norm of the state-dependent input delay model is smaller that the one with fixed delay as for the complete model. In the same way, the fit coefficients remain around $92 \%$ for constant of varying inputs with various frequencies and duty cycles which is typically higher than the values obtained in [20] and that the correlation coefficient between data and model output is very high, typically around $99.9 \%$, meaning that our model capture well enough the dynamics of the averaged data.

As for the non-averaged model, Fig. 10 presents the simulation results of the averaged data set $\mathrm{N}^{\circ} 2$ using identified coefficients for the averaged model. For the 4 concatenated data sets, the leastsquare errors are $\varepsilon_{1}=5.5275$ for the averaged model with constant input delay and $\varepsilon_{2}=4.8734$ for the averaged model with state-

\begin{tabular}{|c|c|c|c|c|c|c|}
\hline \multirow[t]{2}{*}{ Set of data } & \multicolumn{3}{|c|}{ Fixed delay } & \multicolumn{3}{|c|}{ State-dependent delay } \\
\hline & $\varepsilon_{1}$ & $\mathrm{FIT}_{1}$ & $\rho_{1}$ & $\varepsilon_{2}$ & $\mathrm{FIT}_{2}$ & $\rho_{2}$ \\
\hline Data set $\mathrm{N}^{\circ} 1$ (constant) & 2.57 & $94.84 \%$ & 0.9991 & 2.32 & $95.34 \%$ & 0.9992 \\
\hline $\begin{array}{c}\text { Data set } \mathrm{N}^{\circ} 2(f=4 H z, \\
D C=50 \%)\end{array}$ & 6.82 & $86.21 \%$ & 0.9979 & 2.72 & $94.49 \%$ & 0.9987 \\
\hline $\begin{array}{c}\text { Data set } \mathrm{N}^{\circ} 3(f=4 H z, \\
D C=80 \%)\end{array}$ & 3.19 & $93.63 \%$ & 0.9994 & 1.62 & $96.77 \%$ & 0.9995 \\
\hline $\begin{array}{c}\text { Data set } \mathrm{N}^{\circ} 4(f=8 \mathrm{~Hz}, \\
D C=50 \%)\end{array}$ & 5.76 & $88.38 \%$ & 0.9976 & 2.90 & $94.14 \%$ & 0.9987 \\
\hline $\begin{array}{l}\text { Data set not used in } \\
\text { identification } \mathrm{N}^{\circ} 1 \\
\text { (constant) }\end{array}$ & 4.05 & $92.07 \%$ & 0.9978 & 2.83 & $94.45 \%$ & 0.9985 \\
\hline $\begin{array}{l}\text { Data set not used in } \\
\text { identification } \mathrm{N}^{\circ} 2 \\
(f=8 \mathrm{~Hz}, D C=80 \%)\end{array}$ & 3.40 & $93.25 \%$ & 0.9990 & 2.45 & $95.12 \%$ & 0.9991 \\
\hline Concatenated data sets & 10.23 & $89.72 \%$ & 0.9969 & 4.87 & $95.10 \%$ & 0.9988 \\
\hline
\end{tabular}

TABLE III: Comparison of $L_{2}$ norm values, FIT coefficients and correlation for state-dependent and fixed input delay models for the averaged model

TABLE IV: Values of the delays and identified coefficients for the averaged model (all values have No Unit) for the averaged model

\begin{tabular}{ccc} 
& Fixed delay & State-dependent delay \\
\hline$\tau_{i}^{\text {avg }}$ & {$\left[\begin{array}{c}1 \\
269\end{array}\right]$} & {$\left[\begin{array}{c}6 \\
384\end{array}\right]$} \\
\hline $\bar{\tau}_{i}^{\text {avg }}$ & {$\left[\begin{array}{c}1 \\
307\end{array}\right]$} & {$\left[\begin{array}{c}6 \\
454\end{array}\right]$} \\
\hline$h_{l}^{\text {avg }}$ & {$\left[\begin{array}{c}49 \\
417\end{array}\right]$} & $f^{\text {avg }}=\left[\begin{array}{c}1.5513 \\
106.7560\end{array}\right]$ \\
\hline$a_{i}^{\text {avg }}$ & {$\left[\begin{array}{c}1.0027 \\
-0.0027\end{array}\right]$} & {$\left[\begin{array}{c}1.0117 \\
-0.0121\end{array}\right]$} \\
\hline$b_{l}^{\text {avg }}$ & {$\left[\begin{array}{c}0.0009 \\
0.0030\end{array}\right]$} & {$\left[\begin{array}{l}0.0096 \\
0.0000\end{array}\right]$} \\
\hline & {$\left[\begin{array}{c}-0.0008 \\
0.0045 \\
-0.0085 \\
0.0010\end{array}\right]$} & {$\left[\begin{array}{c}-0.0179 \\
0.0088 \\
-0.0490 \\
0.0208\end{array}\right]$}
\end{tabular}

dependent input delay. Again, the model using state dependent input delays gives better performances in term of the $L_{2}$ norm. It is to be noted that a longer series of 0 have been added at the end of each data set than in the non averaged case, in order to ensure that the averaged system has enough time to go back to 0 between each set.

\section{Identification results}

Now that the identification is completed, we can apply the identified models to each data set separately. Fig. 9 depicts the outputs of the model and real plant for the data set $\mathrm{N}^{\circ} 2$. In the same way, Fig. 10 depicts the outputs of the averaged identified model for data set $\mathrm{N}^{\circ} 2$.

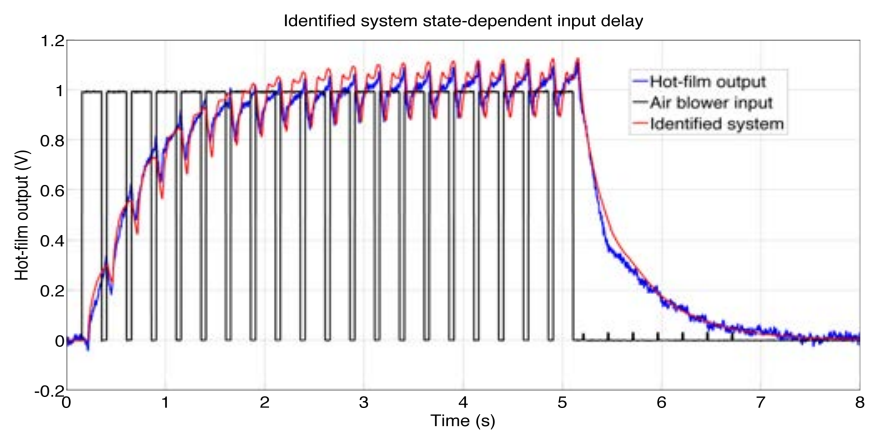

Fig. 9: Identified model with state-dependent input delay, zoom on data set $\mathrm{N}^{\circ} 3$ 


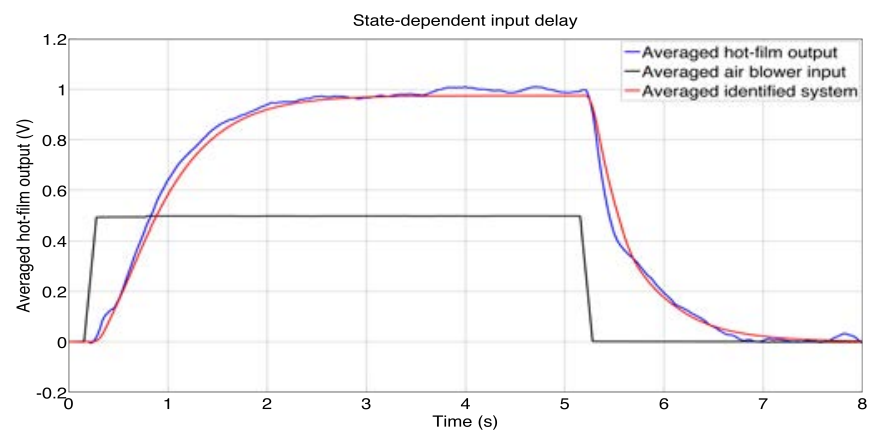

Fig. 10: Averaged identified model with state-dependent input delay, zoom on data set $\mathrm{N}^{\circ} 3$

It can be seen that both models follow closely enough the data but, again, the model using state-dependent input delay is better. There are some inaccuracies mainly around peaks but these are caused partly by noise in the data signal, the fact that we wish to fit several type of input-output and the simplicity of our model as we do need seek exact fitting but good tendency estimation, which is what we get here.

\section{CONCLUSIONS AND FUTURE WORKS}

The identification of a highly nonlinear model using a discrete bilinear state and input delayed system has been proposed. Two cases have been presented : one where the input delay is constant and one where it is state-dependent. The results showed that the state-dependent case is more reliable in the $L_{2}$ sense for simulation.

The next step concerns the application to close-loop control : our ongoing work, presently limited to simulation, shows these model can have a valuable contribution to flow control. However, due to length constrain and preliminary nature of this extension, we do not consider it here. We will only show a plot in Fig. 11 obtained in simulation of the effect of a control designed in order to maximize the friction gain of the averaged model. It can be observed that the friction gain takes values higher than 1 , with an average around 1.2 , resulting in a approximately $20 \%$ increase compared to the control signals used previously. Then, the design of an appropriate nonlinear control can lead to improvement in the friction gain and then in the reattachment of the separation.

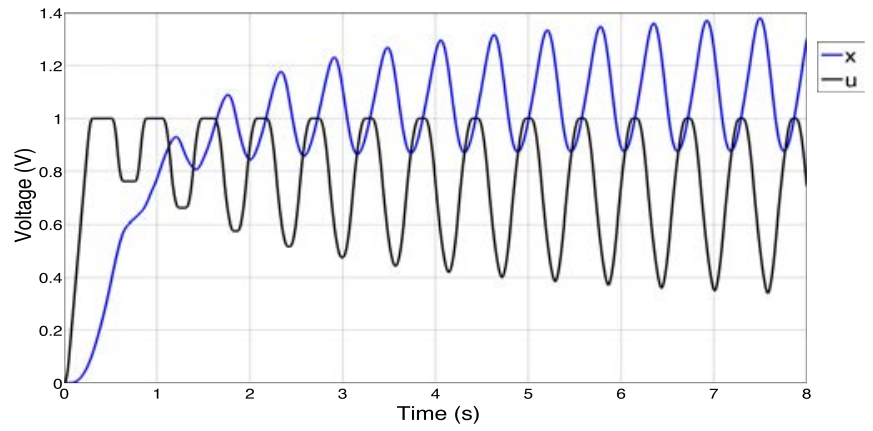

Fig. 11: Testing of a nonlinear control input

\section{ACKNOWLEDGMENTS}

This work was supported by the Région Nord Pas-de-Calais in the framework of the ELSAT-CISIT program.

\section{REFERENCES}

[1] C. Raibaudo, F. Kerherve, and M. Stanislas, "Characterisation of the transient dynamics of a controlled separated flow using phase averaged PIV," in International Conference on Instability and Control of Massively Separated Flows - ICOMASEF, 2013.
[2] C. Raibaudo, A. Polyakov, D. Efimov, F. Kerherve, J.-P. Richard, and M. Stanislas, "Experimental closed-loop control of a detached boundary layer at high Reynolds number," in 10th EUROMECH Fluid Mechanics Conference, 2014.

[3] T. Chabert, J. Dandois, É. Garnier, and L. Jacquin, "Experimental detection of flow separation over a plain flap by wall shear stress analysis with and without steady blowing," Comptes Rendus Mécanique, vol. 342, no. 6, pp. 389-402, 2014.

[4] T. Chabert, J. Dandois, and É. Garnier, "Experimental closed-loop control of flow separation over a plain flap using slope seeking," Experiments in Fluids, vol. 55, no. 8, pp. 1-19, 2014.

[5] T. Shaqarin, C. Braud, S. Coudert, and M. Stanislas, "Open and closedloop experiments to identify the separated flow dynamics of a thick turbulent boundary layer," Experiments in Fluids, vol. 54, pp. 1-22, Jan. 2013.

[6] G. V. Selby, J. C. Lin, and F. G. Howard, "Control of low-speed turbulent separated flow using jet vortex generators," Experiments in Fluids, vol. 12, pp. 394-400, Apr. 1992

[7] K. B. Chun and H. J. Sung, "Control of turbulent separated flow over a backward-facing step by local forcing," Experiments in Fluids, vol. 21, pp. 417-426, Nov. 1996.

[8] E. Åkervik, J. Hoepffner, U. Ehrenstein, and D. S. Henningson, "Model reduction and control of a cavity-driven separated boundary layer," in IUTAM Symposium on Flow Control and MEMS, pp. 147-155, Springer, 2008. bibtex: akervik_model_2008.

[9] D. Wachsmuth, Optimal control of the unsteady Navier-Stokes equations. $\mathrm{PhD}$ thesis, $\mathrm{PhD}$ thesis, Technische Universität Berlin, 2006.

[10] O. Ghattas and J.-H. Bark, "Optimal Control of Two- and ThreeDimensional Incompressible Navier-Stokes Flows," Journal of Computational Physics, vol. 136, pp. 231-244, Sept. 1997.

[11] E. Fernández-Cara, S. Guerrero, O. Y. Imanuvilov, and J. P. Puel, "Local exact controllability of the Navier-Stokes system," Journal de Mathématiques Pures et Appliquées, vol. 83, pp. 1501-1542, Dec. 2004.

[12] H. Jin-quan and F. Lewis, "Neural-network predictive control for nonlinear dynamic systems with time-delay," IEEE Transactions on Neural Networks, vol. 14, pp. 377-389, Mar. 2003.

[13] S. C. Jeong and P. Park, "Constrained MPC algorithm for uncertain time-varying systems with state-delay," IEEE Transactions on Automatic Control, vol. 50, pp. 257-263, Feb. 2005.

[14] M. V. Kothare, V. Balakrishnan, and M. Morari, "Robust constrained model predictive control using linear matrix inequalities," Automatica, vol. 32, pp. 1361-1379, Oct. 1996.

[15] G. M. Schoen, Stability and stabilization of time-delay systems. PhD thesis, Swiss Federal Institute of Technology Zurich, 1995.

[16] S. Le Digabel, "Algorithm 909: NOMAD: Nonlinear optimization with the MADS algorithm," ACM Transactions on Mathematical Software (TOMS), vol. 37, no. 4, p. 44, 2011.

[17] F. Veysset, L. Belkoura, P. Coton, and J.-P. Richard, "Delay system identification applied to the longitudinal flight of an aircraft through a vertical gust," in 14th Mediterranean Conference on Control and Automation, 2006. MED '06, pp. 1-6, June 2006.

[18] J. Carlier and M. Stanislas, "Experimental study of eddy structures in a turbulent boundary layer using particle image velocimetry," Journal of Fluid Mechanics, vol. 535, pp. 143-188, July 2005.

[19] L. Ljung, System identification - Theory for the User. Prentice-Hall, 1999.

[20] J. Dandois, E. Garnier, and P.-Y. Pamart, "NARX modelling of unsteady separation control," Experiments in fluids, vol. 54, no. 2, pp. 1-17, 2013.

[21] C. Audet, J. E. D. Jr, and S. L. Digabel, "Globalization strategies for Mesh Adaptive Direct Search," Computational Optimization and Applications, vol. 46, pp. 193-215, June 2009.

[22] C. Audet, V. Béchard, and S. L. Digabel, "Nonsmooth optimization through Mesh Adaptive Direct Search and Variable Neighborhood Search," Journal of Global Optimization, vol. 41, pp. 299-318, Oct. 2007.

[23] C. Audet and J. Dennis, "Mesh Adaptive Direct Search Algorithms for Constrained Optimization," SIAM Journal on Optimization, vol. 17, pp. 188-217, Jan. 2006.

[24] J. Currie and D. I. Wilson, "OPTI: Lowering the Barrier Between Open Source Optimizers and the Industrial MATLAB User," in Foundations of Computer-Aided Process Operations (N. Sahinidis and J. Pinto, eds.), (Savannah, Georgia, USA), Jan. 2012 